\title{
La chica danesa
}

\section{The Danish Girl| Tom Hooper | 2015}

\author{
Pilar Ordóñez"
}

Escuela de la Orientación Lacaniana

Recibido: 18 de mayo 2016; aprobado: 17 de junio 2016

\begin{abstract}
Resumen
Este escrito versa sobre un film que invita a hablar a un personaje que tuvo su correlato en la historia de la pintura, Einar Morgens Wegener. Como así también en la historia de los derechos humanos que protegen la diversidad sexual.Se desarrolla la idea que la experiencia analítica, al igual que la ficción que muestra La chica Danesa, se trata de amor y de goce. Se trata del encuentro con alguien que invita a tomar la palabra y de ese encuentro puede resultar una transformación.
\end{abstract}

Palabras clave: Sexuación | Psicoanálisis | Hablanteser | Posición femenina

Abstract

This essay is about a character that had its counterpart in the history of painting, Einar Wegener Morgens. As well as in the history of human rights that protects sexual diversity. Shows the idea that the analytic experience, like the fiction showing by the Danish girl, is about love and jouissance. It is the encounter with someone who invites to speak and that meeting can provoke a transformation.

Keywords: Sexuation | Psychoanalysis | Speaking being | Feminine position

\section{Tomar la palabra}

Este film invita a hablar a un personaje, Einar Morgens Wegener (1882-1931), que tuvo su correlato tanto en la historia de la pintura como en la historia de los derechos humanos que protegen la diversidad sexual.

No reconozco un acto más humano que invitar a tomar la palabra. Pueden pasar cosas insospechadas. La palabra tiene un circuito bien conocido para quienes estudian y se forman en esta disciplina crítica que llamamos psicoanálisis. Un circuito que contradice los esquemas clásicos de la comunicación. Porque el mayor efecto no es para el receptor del mensaje, sino para el emisor. Ese efecto hace que el mensaje retorne de manera invertida sobre quien habla. La tesis sostiene: la experiencia analítica, al igual que la ficción que muestra La chica Danesa (Hooper, 2015), se trata de amor y de goce. Se trata del encuentro con alguien que invita a tomar la palabra y de ese encuentro puede resultar una transformación.

Lo más curioso del circuito de la palabra es que el sentido de lo que alguien expone lo decide quien escu- cha. El emisor puede tener intenciones de decir algo muy preciso, pero quien va a decidir el contenido y el peso del mensaje es el discrecional del oyente deja a quien habla en una indeterminación, produce una división. Esa división es un efecto muy importante para la experiencia del psicoanálisis. Pero no es el único. El psicoanálisis atiende también el efecto que ciertos tonos, ciertos silencios tienen sobre el cuerpo, es lo más interesante de la experiencia de hablar dirigiéndose a Otro. ¿Por qué explicitar este circuito? Porque trabajaremos sobre las conceptualizaciones que tocan el problema del goce sexual, aquello que en la Koiné se denomina sexo. En pleno siglo XXI, ciertas palabras pueden despertar afectos tan disímiles como el pudor, el rechazo, la indignación. El aburrimiento suele ser el menos frecuente, pero no lo descartemos. Esto se debe a que el sexo se apoya en un elemento transhistórico, en una invariante. A pesar de las modas, los gustos de época y las revoluciones, el sexo encuentra siempre su hora revulsiva. De hecho un autor como Michel Foucault, quien se dedicó a hacer arqueologías de temas caros a la humanidad, cuando quiso

pilaroz@yahoo.com.ar 
hacer la arqueología de la sexualidad humana, el tema se le volvió extenso y resbaladizo. Sus tres tomos lo certifican. Porque existe una dimensión del sexo que escapa a todo intento de historización, de dominio o de civilidad.

El título del ciclo que enmarca esta exposición permite equivocaciones y tonos diversos: Sólo sexo. Elegí una variación del título para orientar el comentario: ¿Un solo sexo? Más aún, ¿Cuántos sexos? ¿Uno, dos, veinticuatro? ¿Hay un sexo biológico? ¿La anatomía es un destino? ¿Hay un sexo determinado por la cultura? ¿Con un sexo se nace? ¿Un sexo se decide? Este es el nudo que abordaremos.

Evitaremos suponerle una subjetividad a los personajes, es decir que no los interpretaremos como si se tratara de personas. Puede refutarse: ¡pero está basada en hechos reales! Es cierto. Pero, para el psicoanálisis lo real tiene otro estatuto y los analistas sólo analizan a gente de carne y hueso. Por eso decididamente evitaremos las reflexiones de tipo diagnóstica o psicopatológica y cualquier animismo. Trataremos de servirnos de algunos elementos que brinda esta ficción para ubicar el problema de la sexuación.

\section{Error común}

Partamos de la división que se realiza comúnmente. Generalmente, fruto de la debilidad mental que acompaña al hablanteser, tendemos a armar una clasificación bipartita.

Nenas y nenes, damas y caballeros, normales y raros, los que tienen y los que no tienen pene. Esta división que Lacan (1971-1972 [2012]) va a calificar como el "error común” (p. 17) ${ }^{1}$, aparece con cierta ingenuidad al inicio de este film. Para ello se utiliza la metáfora de los artistas que se dedican a pintar paisajes y los que se dedican a pintar retratos. Los que pintan el mundo son los hombres, las que pintan la intimidad son mujeres. Esta es una división que responde al error común y por ejemplo suele encasillarse así a Frida Kahlo y a Diego Rivera ${ }^{2}$. Pero lo interesante de esta película es que esta clasificación se desarma enseguida porque resulta que el paisaje de Einer (Eddie Redmayne) no responde al mundo exterior. Ese paisaje es la expresión de una memoria, ese paisaje recubre la fijación de una experiencia íntima. En la ficción se cuenta un recuerdo infantil, el beso con un amigo y sus consecuencias. Einar, ha montado un pequeño motivo, que conmemora su encuentro con ese goce sexual. Ese motivo no cubre de una vez y para siempre el agujero de sentido que el goce ha producido. Ese paisaje perenne, inmóvil es la pantalla que recubre una marca en el cuerpo. Una marca que late, una marca viva, que empuja una y otra vez a reeditar el mismo cuadro. Con esa invención Einar se ha hecho un nombre y un lugar en el ambiente del arte. Entonces, él pinta por motivos muy íntimos un paisaje que poco importa que tenga su referente en algún lugar del mundo exterior.

Por el contrario, Gerda (Alicia Vikander), pinta retratos, que supuestamente captarían lo más íntimo. Pero el resultado no le es muy propicio. En una escena, el galerista danés, Rasmussen (Adrian Schiller), le dice que esos retratos no son un material valioso. Porque reflejan como un calco mimético los rostros pero no captan lo más íntimo. Recién cuando Gerda capta en sus dibujos a Lili (Eddie Redmayne), una Lili que no existe como tal, pero que ella interpreta en el rostro de su marido, su trabajo alcanza ese toque que se necesita para atrapar la mirada.

Así la película señala el error común: la división binaria hombres, mujeres; interior, exterior; realidad, fantasía, resulta inoperante y reduccionista. Habrá que recurrir a otras categorías más complejas.

Para el psicoanálisis no existen dos sexos. Sólo existen posiciones sexuadas, tantas como personas haya y no admiten clasificaciones. En todo caso, se puede recurrir a lo que Jean-Claude Milner (1999) denomina clases paradojales. Las clases paradojales son singulares, en el sentido de que admiten un único ejemplar o referente.

Tampoco existe una división entre mundo interior y mundo exterior. El psicoanálisis, de orientación lacaniana, acuña una noción que es la extimidad, un mixto extraño resuelto en una inspiración topológica. Algo late en lo más íntimo de cada hablante ser, pero no le es posible reconocerse tan sencillamente en eso que lo habita. Lo más íntimo resulta extranjero y por eso a veces hablamos con un psicoanalista, ese perfecto extraño, quien nos permite reconocernos en esa extimidad. No hay realidad objetiva y fantasía subjetiva. Sólo cuenta lo que desde Freud llamamos realidad psíquica.

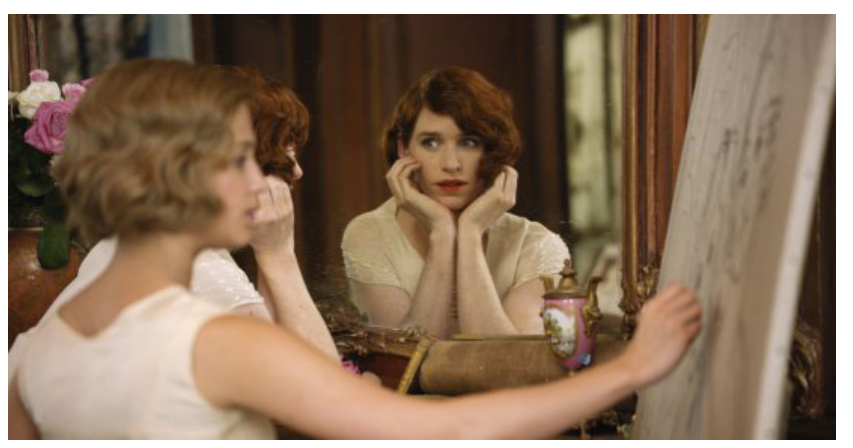




\section{Reflejo y velo}

A lo largo de la película se pueden apreciar dos recursos que podemos diferenciar y destacar: el reflejo en el espejo y el uso del velo. Ambos son recursos estéticos, pero también son recursos subjetivos. El primero, el reflejo en el espejo, se corresponde con una experiencia universal, para todos los seres hablantes. Depende de cómo pueda servirse de ese reflejo y su poder estructurante, dependiendo de cómo resulte esa experiencia, contará con más o menos tácticas para sobrellevar el hecho de tener un cuerpo sexuado. En la enseñanza de Lacan (1998) se conoce como el "estadio del espejo" a ese primer encuentro con la imagen del propio cuerpo. En la película aparece por doquier. Einer en el espejo, en los vidrios de las ventanas, en la cabina del prostíbulo mimetizándose con los gestos de la prostituta, mirándose frente a las pinturas de Gerda. El poder estructurante del espejo consiste en que, al reconocer ese reflejo, el cuerpo cobra unidad, se compone una gestalt anticipada que responde a la buena forma. Salvo que aparezca algo de más en esa imagen, algo que no debería aparecer en el reflejo y de eso resulta la ominosa sensación de desconocimiento o despersonalización, de sentir que ese cuerpo no es propio. Hay experiencias muy fuertes, como la que ilustra el pasaje en que Einer compone una pose que esconde el pene para poder reconocerse ${ }^{3}$. Pero también existen experiencias atenuadas de esta vacilación del espejo ${ }^{4}$. Entonces, el trabajo que Einer se toma frente al espejo no es una cuestión de narcisimo o vanidad. Es un trabajo estructurante de la subjetividad, que en general se toman los seres hablantes con mayor o menor fortuna. Suele decirse que las mujeres pasan más tiempo frente al espejo que los hombres. Podría tener alguna razón. Los seres hablantes que asumen una posición femenina se encuentran en una encrucijada. Una mujer nunca es idéntica consigo misma, siempre es un poco Otra para sí misma. Las horas en el espejo podrían ser el intento de atenuar esa otredad. Un intento de atemperar esa alteridad radical. Otro modo de atenuar la alteridad propia de la feminidad es hacer consistir la figura de la otra mujer. La otra mujer es un recurso muy explotado en la histeria. Para acceder a esa otra mujer, la histeria toma a un hombre como relevo. Ese hombre es un hombre de paja, según la denomina Lacan. Es decir que la histeria se sirve de un hombre para que este le traiga a la otra mujer. En la película se ven dos procedimientos que podríamos llamar histéricos. Uno es el que Gerda practica al pintar el rostro de Lili, apoyada en el rostro de Einer, su marido. Es un pedido insistente, una solicitud imperativa. Consigue encontrar la otra en ese rostro. El otro procedimiento histérico se ve cuando Gerda está en su propia exposición en París. Un hombre se le acerca para abordarla, es un amigo que nunca ha disimulado demasiado sus intenciones. Ella lo rechaza. Él sigue camino por unas escaleras y se acerca a otra mujer, para susurrarle seductoramente algo en el oído. Eso la angustia terriblemente a Gerda, que sale corriendo de la sala a caminar bajo la lluvia. La angustia y la orienta respecto de su deseo. La siguiente escena la muestra en otra escalera, en el lugar de la otra mujer, esperando al caballero, para arrojarse en sus brazos. La pregunta por la feminidad queda así enmarcada, al modo histérico.

Por otro lado, el velo es un motivo que atraviesa toda la historia. Está en el lienzo que soporta la pintura, en la chalina, en el dosel de la cama matrimonial, en los vestidos.

En la historia aparece un primer velo. El que ubiqué en la pintura monotemática de Einer. Esa pintura vela, es decir cubre y señala al mismo tiempo su primer encuentro con el goce sexual. Es un velo que funciona hasta que ocurre otro pequeño- gran acontecimiento. Se perturba por primera vez, cuando Gerda le pide que pose, en lugar de Ulla, la bailarina. Entonces aparece otra tela, la del vestido. Con esta substitución del lienzo por los tules se produce un cambio de posición respecto de la mirada. No es él quien mira (el paisaje), él es ahora mirado. Al posar para el retrato se posiciona como objeto de una mirada, la de Gerda, que es una mirada que lo anima, lo empuja a tomar los tules. Entonces en el relato ocurre algo muy particular. La cámara toma el punto de mira de Einer, asume ese punto de vista y recorre los tules y las piernas con una imagen fuera de foco. Es una imagen borrosa. Es la primera conmoción del velo. El velo, según esta lectura, se rasga, deja de cumplir su función, cuando vuelve a encontrarse con el beso de un hombre. Va a la fiesta de los artistas vestido de Lili. Allí se encuentra con Henrik Sandahl, salen del salón y ocurre algo que desbarata el velo que hasta aquí venía funcionando. Al punto que comienza a sangrarle la nariz. Acto seguido se lo ve pintando un paisaje que si bien conserva alguna reminiscencia del anterior, los colores y las formas se han alterado. Llegará a decir en algún momento de la historia "Ya no recuerdo el paisaje, ya no recuerdo Vejle".

Encontré una referencia en un texto del psicoanalista francés J.-A. Miller sobre el tema del velo. En un texto que se titula "Los divinos detalles" (2010), este lúcido comentador de Lacan, señala que se podría distinguir la función que cumple el velo en la posición femenina y en la posición transexual. 
La posición femenina, puede usar el velo bajo la forma del postizo. Es una forma del velo que hace creer que hay algo que no hay. La posición femenina puede usar el maquillaje, la peluca, las ropas llamativas, el push up de los corpiños, y cuanto chirimbolo sea necesario, tratando de velar la ausencia de un significante que le permitiría ser idéntica a sí misma. Los seres que asumen esta posición lo hacen a riesgo de tener que inventar algo, justo allí donde este significante falta. Justo donde falta la palabra que despejaría el enigma de qué es ser una mujer. El velo es el disfraz que viene a tapar lo que no se sabe, ¿qué es ser una mujer? Es algo de lo que no se puede decir demasiado. Cada mujer hace su intento.

En cambio, el uso del velo en la posición transexual viene a tapar lo que sí hay. Porque llamaremos, desde esta perspectiva del psicoanálisis lacaniano, posición transexual a esa posición que sí sabe que es una mujer, sí tiene un significante para nombrarse y, como sí tiene significante, el velo trans viene a tapar lo que sí hay. El velo es el disfraz que viene a realizar lo que sí se sabe.
Se sabe que se es mujer y no hombre. En la película, Einer sabe que es una mujer y no un pervertido, ni un homosexual, ni un esquizofrénico, tal como los hombres de ciencia le quieren hacer creer.

\begin{abstract}
Al final...
La posición sexual no depende de la herencia biológica, ni de las determinaciones culturales, pero tampoco es la libre elección de un yo autónomo. Quiero decir que sería una ilusión pensar que podemos elegir qué posición tomar a partir del catálogo de las clasificaciones, como si fuera un menú. La posición sexuada requiere de una asunción. Tomo este término de la enseñanza de Lacan. La asunción implica aceptar una responsabilidad. Es decir aceptar y responder por las marcas de goce que singularizan a cada ser hablante. Responder por esas marcas que son tan íntimas y a la vez tan extrañas. La asunción de la posición sexuada es una tarea que cada ser hablante tiene.
\end{abstract}

\section{Referencias}

Lacan, J. (1971-1972 [2012]) “...o peor” en El Seminario de Jacques Lacan. Libro 19. Buenos Aires: Paidós.

Lacan, J. (1998) “El estadio del espejo como formador de la función del yo (je) tal como se nos revela en la experiencia psicoanalítica” en Escritos 1 Buenos Aires: Siglo XXI.

Miller, J.A. (2010) “Los Divinos detalles” en Los Cursos Psicoanalíticos de Jacques-Alain Miller. Buenos Aires: Paidós.

Milner, J. C. (1999) Los nombres indistintos. Buenor Aires: Manantial.

$1 \quad$ Sostiene Lacan en El Seminario 19: “(...) el sexo no define ninguna relación en el ser hablante” (p, 13). Luego, en la página 17 del mismo Seminario, refiere que el error común es reducir el falo al órgano, tratando de forzar esa reducción se pierde de vista que el significante es causa de goce y el falo es su significado.

2 Es frecuente leer que Diego Rivera pinta la Revolución y Frida Kahlo las desventuras íntimas de un cuerpo femenino. De más está decir que esa es una reducción que breva de una ideología simplista y naturalizante.

3 En El Seminario 10 La Angustia, Lacan se refiere a estos fenómenos en la página 133, dice: “(...) entre los fenómenos que acompañan la angustia los más conocidos son los de despersonalización. Son precisamente los fenómenos más contrarios al yo en cuanto tal”

4 Les habrá pasado alguna vez que se cortaron el pelo, o cambiaron de peinado y al pasar por una vidriera no se reconocen de buenas a primeras. 